\title{
A case report of fungal infection associated acute fibrinous and organizing pneumonitis
}

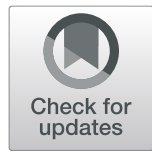

Jiangnan Zhao ${ }^{1}$, Yi Shi ${ }^{1}$, Dongmei Yuan ${ }^{1}$, Qunli Shi ${ }^{2}$, Weiping Wang ${ }^{3}$ and Xin Su ${ }^{1 *}$ (D)

\begin{abstract}
Background: Acute fibrinous and organizing pneumonitis (AFOP) is an uncommon variant of acute lung injury, characterized by intra-alveolar fibrin and organizing pneumonia. Proposed etiologies include connective tissue diseases, infections, occupational exposure, drug reactions, and autoimmune disease. Here we present a rare case of fungal infection associated AFOP in patient with diabetes mellitus (DM) and review the relevant literature.

Case presentation: A 67-year-old man complained of cough, fever, dyspnea and hemoptysis. Patient experienced a rapidly progressive course exhibit diffuse predominant consolidation, ground glass opacities, and multifocal parenchymal abnormalities on chest computed tomography (CT). Antibacterial, antifungal, and antiviral treatments were ineffective. A CT-guided percutaneous lung biopsy was performed. Histologically, the predominant findings were as follows: alveolar spaces filled with fibrin and organizing loose connective tissues involving $70 \%$ of the observed region, pulmonary interstitial fibrosis, and small abscesses and epithelioid cell granuloma in the focal area. Result of periodic acid-silver methenamine stain was positive. The fungal pathogen from the sputum culture was identified as P. citrinum repeatedly over 3 times. Patient was diagnosed with DM during hospitalization. Corticosteroids combined with an antifungal therapy were effective. Follow-up for 4 months showed complete radiological resolution.

Conclusions: As this common "contaminant" can behave as a pathogen in the immunocompromised host, both clinicians and microbiologists should consider the presence of a serious and potentially fatal fungal infection on isolation of P. citrinum. Based on this case, it could be speculated that AFOP may be associated with fungal infection including $P$. citrinum.
\end{abstract}

Keywords: Acute fibrinous and organizing pneumonitis, Penicillium citrinum, Infection, Case report

\section{Background}

Acute fibrinous and organizing pneumonitis (AFOP) is a rare form of idiopathic interstitial pneumonia (IIP), which has currently been increasingly recognized and added to the American Thoracic Society/European Respiratory Society (ATS/ERS) international multidisciplinary classification of IIP [1]. AFOP is a rare histopathological diagnosis, which is characterized by organized intra-alveolar fibrin. AFOP can be idiopathic or

\footnotetext{
* Correspondence: suxinjs@163.com

'Department of Respiratory and Critical Care Medicine, Jinling Hospital,

Medical School of Nanjing University, Nanjing 210002, China

Full list of author information is available at the end of the article
}

associated with known causes, such as connective tissue disorders, drugs, occupational exposure, immune system disorders, and infections [2-5], requiring prompt clinical evaluation. Clinical characteristics associated with this disease are non-specific and vary widely. To the best of our knowledge, there have been no reports on AFOP associated with fungal infections. We present a case of AFOP combined with fungal infection, which presented with a rapidly progressive clinical course and radiological findings, and responded well to corticosteroids combined with an antifungal treatment.

(c) The Author(s). 2020 Open Access This article is licensed under a Creative Commons Attribution 4.0 International License, which permits use, sharing, adaptation, distribution and reproduction in any medium or format, as long as you give appropriate credit to the original author(s) and the source, provide a link to the Creative Commons licence, and indicate if changes were made. The images or other third party material in this article are included in the article's Creative Commons licence, unless indicated otherwise in a credit line to the material. If material is not included in the article's Creative Commons licence and your intended use is not permitted by statutory regulation or exceeds the permitted use, you will need to obtain permission directly from the copyright holder. To view a copy of this licence, visit http://creativecommons.org/licenses/by/4.0/ The Creative Commons Public Domain Dedication waiver (http://creativecommons.org/publicdomain/zero/1.0/) applies to the data made available in this article, unless otherwise stated in a credit line to the data. 


\section{Case presentation}

A 67-year-old man, former smoker (20 pack-year), complained of cough with white mucous sputum for over 2 weeks and developed fever for 3 days. The medical history included hypertension, which was well-controlled with nifedipine.

Blood investigations at a local hospital revealed a white blood cell (WBC) count of $19.17 \times 10^{9} / \mathrm{L}$, and markedly elevated C-reactive protein (CRP) level $(242.26 \mathrm{mg} / \mathrm{L})$. Initial chest computed tomography (CT) on March 22 showed bilateral scattered consolidation areas (Fig. 1a). Empirical therapy was provided for community-acquired pneumonia (CAP) with piperacillin-sulbactam, moxifloxacin and ceftriaxone. However, he showed no signs of improvement. Laboratory investigations revealed a positive serum galactomannan (GM) antigen test (1.76), and Aspergillus was isolated from the sputum culture. The patient was treated with fluconazole, but the treatment was ineffective. Chest radiography on March 27 revealed obviously increased bilateral parenchymal opacities (Fig. 1b). As the patient's condition further deteriorated, he was transferred to the Department of Respiratory and Critical Medicine at Jinling Hospital.

On admission, his vital signs were as follows: body temperature, $38.6^{\circ} \mathrm{C}$; pulse rate, 84 beats $/ \mathrm{min}$; respiratory rate, 18 breaths/min; and blood pressure, 129/74
$\mathrm{mmHg}$ and; oxygen saturation on room air, 95\%. Chest auscultation revealed increased breath sounds with fine crackles and wheezing in the upper right lung zones, with no other remarkable findings. The abnormal laboratory test results were as follows: WBC count, $14.25 \times 10^{9} / \mathrm{L}$; neutrophils\%, 81.8; CRP, $69.6 \mathrm{mg} / \mathrm{L}$; albu$\min , 25.0 \mathrm{~g} / \mathrm{L}$; alanine aminotransferase, $109 \mathrm{U} / \mathrm{L}$; procalcitonin, $0.105 \mu \mathrm{g} / \mathrm{L}$; and interleukin-6, $224.60 \mathrm{ng} / \mathrm{L}$. The autoimmune antibody profile, CD4 lymphocyte count, IgM, IgG, IgE and tumor biomarkers were within the normal limits. Other laboratory investigations, including rapid antigen tests for influenza $\mathrm{A}$ and $\mathrm{B}$, the Mantoux test, and the T-spot test, were all negative. However, he had poorly controlled blood sugar during hospitalization. $\mathrm{He}$ received a diagnosis of diabetes mellitus (DM) type 2 from endocrinologist.

Based on the sputum culture, blood GM test, and CT at the local hospital, we initially diagnosed the patient with "probable" invasive pulmonary aspergillosis (IPA) and treated him with voriconazole. However, the patient's clinical status worsened, with persistent fever. The serum GM test result at our hospital was negative. Fiberoptic bronchoscopy with bronchoalveolar lavage (BAL) was performed the following day. On admission day 4, the patient developed exertional dyspnea and hemoptysis. We suspected drug-resistant pneumonia
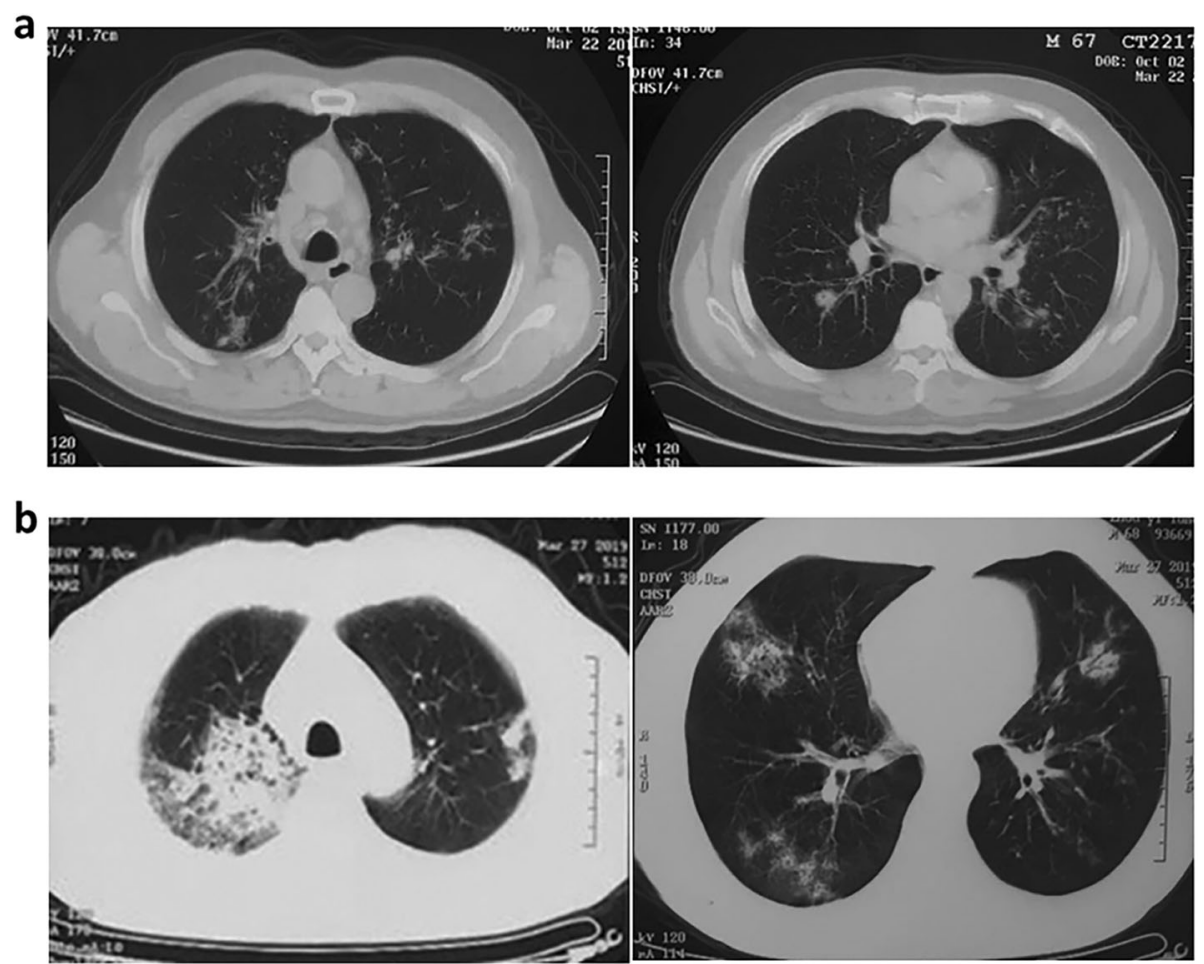

Fig. 1 a CT on March 22 showing bilateral diffuse ground-glass opacities and multi-focal, patchy, ill-defined nodular opacities in the lungs. $\mathbf{b}$ Newly developed multi-focal dense consolidations are observed 


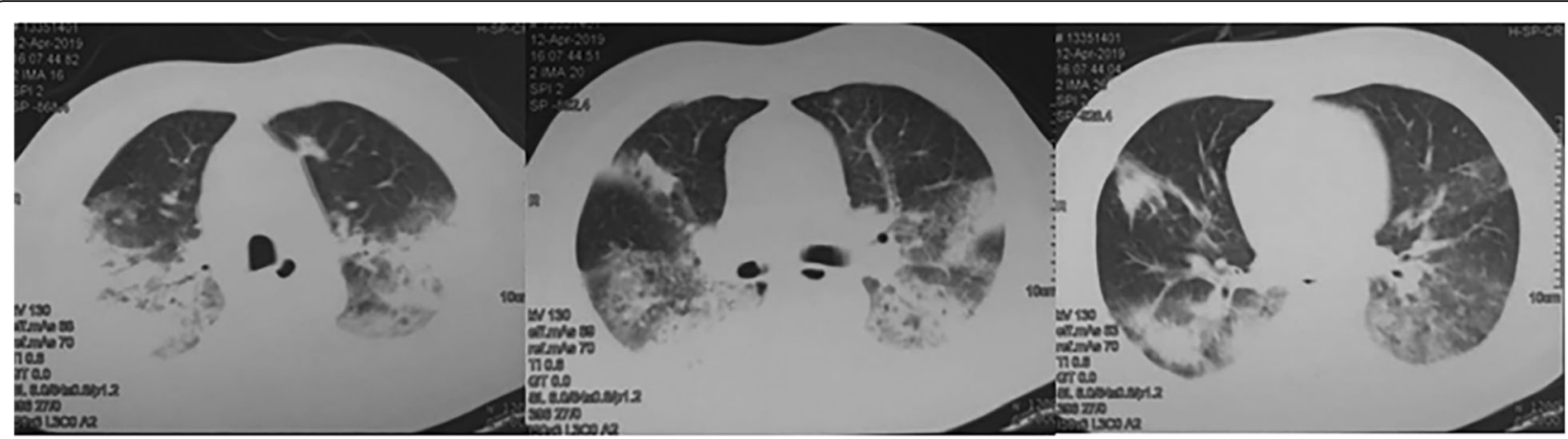

Fig. 2 Bilateral diffuse patchy opacities, multi-focal dense consolidations and bronchial shadows in some lesions are observed

and treated the patient empirically with anti-bacterial (biapenem, linezolid), anti-fungal (caspofungin), and anti-viral (oseltamivir, acyclovir) drugs in succession.

Despite these treatments and supportive care, his respiratory status continued to deteriorate, with persistent hyperthermia. Arterial blood gases analysis showed hypoxemia (partial pressure of oxygen $\left(\mathrm{PaO}_{2}\right)$ /fraction of inspired oxygen $\left.\left(\mathrm{FiO}_{2}\right) 235 \mathrm{mmHg}\right)$. The blood culture, staining for acid-fast bacillus in sputum and BAL fluid, and GM test results in BAL fluid were negative. Smear and culture of Mycobacterium tuberculosis in sputum and BAL fluid were also negative. Emergency contrastenhanced chest $\mathrm{CT}$ on day 10 revealed bilateral diffuse patchy opacities, multi-focal dense consolidations and bronchial shadows in some lesions (Fig. 2). As the antimicrobial drugs were ineffective and organizing pneumonia was considered, the patient was administered with methylprednisolone $40 \mathrm{mg}$ daily; fever subsided, but dyspnea, cough, and hemoptysis underwent progressive worsening. To confirm the diagnosis, we performed a CT-guided percutaneous lung biopsy on day 10. Histologically, the predominant findings were as follows: alveolar spaces filled with fibrin and organizing loose connective tissues involving $70 \%$ of the observed region, pulmonary interstitial fibrosis, and small abscesses and epithelioid cell granuloma in the focal area (Fig. 3a, b, and c). Result of periodic acid-silver methenamine (PAM) stain was positive (Fig. 3 d). The pathological diagnosis was AFOP combined with fungal infection. Methylprednisolone at an increased dose of $40 \mathrm{mg}$ twice a

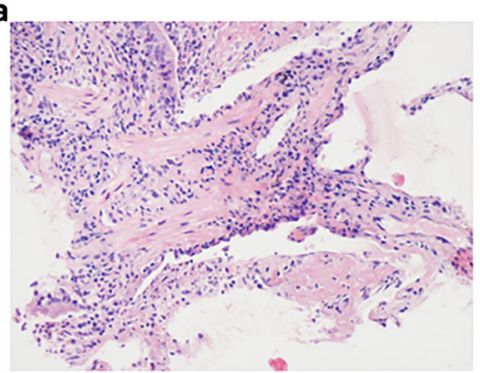

C

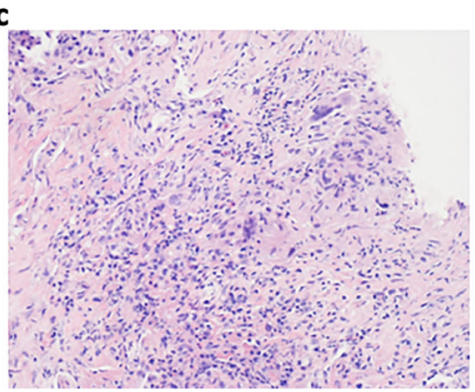

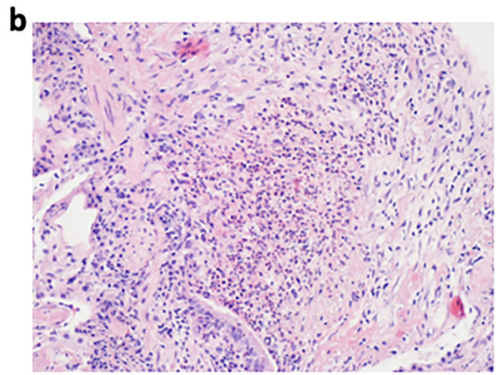

d

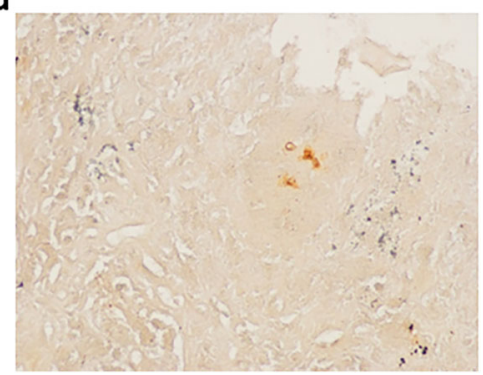

Fig. 3 The lung biopsy findings are consistent with the histological pattern of AFOP combined with a fungal infection. a Alveolar spaces filled with fibrin and organizing loose connective tissues (hematoxylin and eosin [H\&E] stain, $\times 200$ ). $\mathbf{b}$ Infiltrations of abundant neutrophils and some lymphocytes and formation of small abscesses (H\&E stain, $\times 200$ ). $\mathbf{c}$ Epithelioid cell granuloma (H\&E stain $\times 200$ ). $\mathbf{d}$ Periodic acid-silver methenamine (PAM) staining of a lung biopsy specimen revealing spores $(\times 400)$ 


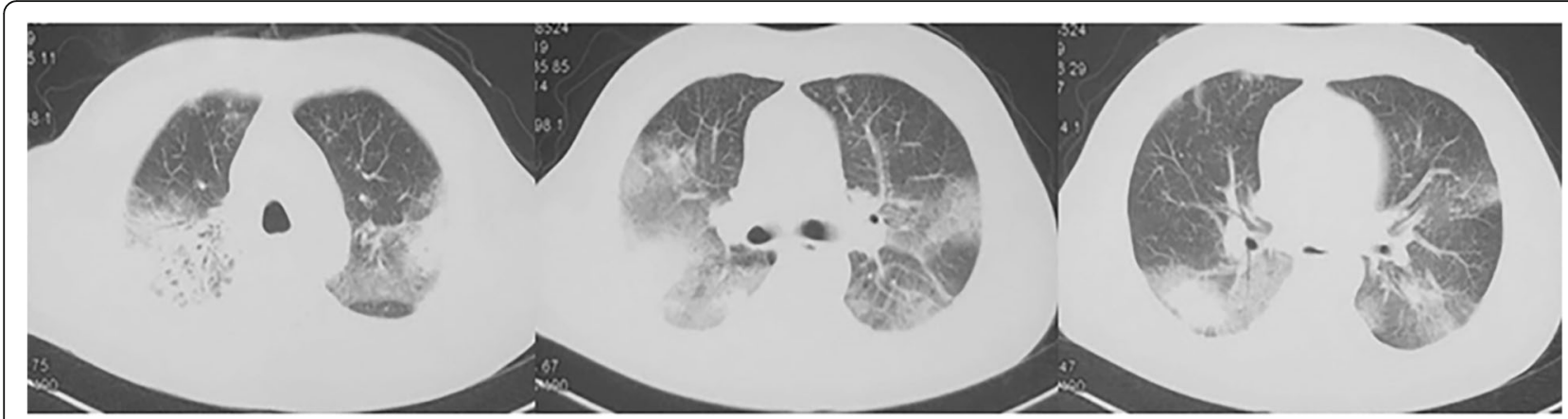

Fig. 4 Increasing bilateral diffuse pulmonary infiltrates in both the lungs

daily and voriconazole were continued. However, his condition steadily deteriorated, with continued hypoxemia (the lowest $\mathrm{PaO}_{2} / \mathrm{FiO}_{2}: 173 \mathrm{mmHg}$ ), chest discomfort and exercise intolerance. CT on day 15 showed worsening of the bilateral patchy opacities (Fig. 4).

On day 16, a 3-day course of intravenous methylprednisolone was started at $500 \mathrm{mg} / \mathrm{d}$ and subsequently, methylprednisolone was continued at $40 \mathrm{mg}$ twice daily. Simultaneously, an antifungal therapy with amphotericin B (dose gradually increased from $10 \mathrm{mg}$ to $40 \mathrm{mg}$ daily) and voriconazole was administered. On day 25 , the dose of methylprednisolone was gradually reduced to $30 \mathrm{mg}$ twice daily. Chest CT revealed reduction in the size of the opacity. On day 30, the dose of methylprednisolone was reduced to $40 \mathrm{mg}$ daily. Because of progressive anemia and thrombocytopenia, amphotericin B was discontinued on day 36 . On day 37 , the patient was switched to oral prednisone ( $40 \mathrm{mg}$ daily) and voriconazole, with a reduced prednisone dose of $5 \mathrm{mg}$ weekly after discharge from the hospital. Steroid tapering was well-tolerated, with no obvious adverse reactions. Four months after the discharge, chest CT showed complete resolution of the lesions.

The fungal pathogen from the sputum culture was identified as $P$. citrinum. The phialides were ampulliform, bearing well-defined chains of spherical to subspherical conidia, with smooth or finely roughened walls (Fig. 5). The fungal pathogen was sent to a reference laboratory (Shanghai Majorbio Bio-pharm Technology Co., Ltd) for identification, and was confirmed as $P$. citrinum with a polymerase chain reaction sequencing analysis. Antifungal sensitivity testing using the Sensititre $^{\text {Tx }}$ YeastOne ${ }^{\text {Tux }}$ YO10 Susceptibility Plate (Trek Diagnostics Systems, West Sussex, UK) revealed that the P.citrinum isolate demonstrated marked in vitro sensitive to amphotericin $\mathrm{B}$ with minimum inhibitory concentration (MIC) of $2 \mu \mathrm{g} / \mathrm{ml}$ and resistance to voriconazole with MIC of $>8 \mu \mathrm{g} / \mathrm{ml}$.

\section{Discussion and conclusions}

Since the concept of AFOP was proposed by Beasley et al. in a case series involving 17 patients in 2002 [3], AFOP cases have been increasingly reported and recognized. In 2013, AFOP was added to the ATS/ERS classification of IIPs [1]. Patients with AFOP can present with various respiratory signs and symptoms. The common clinical symptoms are fatigue, prolonged fever, cough, dyspnea, and hemoptysis with rapid deterioration leading to respiratory failure. On imaging, various radiographic findings have been described [6]. Patients with AFOP who experience a rapidly progressive course often exhibit diffuse predominant consolidation, ground glass opacities, and multifocal parenchymal abnormalities on imaging.

The diagnosis of AFOP relies on the histologic features of a lung biopsy specimen. Our patient was preliminarily diagnosed with CAP; however, antibacterial, antifungal, and antiviral treatments were ineffective. To confirm the diagnosis, a percutaneous lung biopsy was performed; the pathology was consistent with AFOP. Therefore,

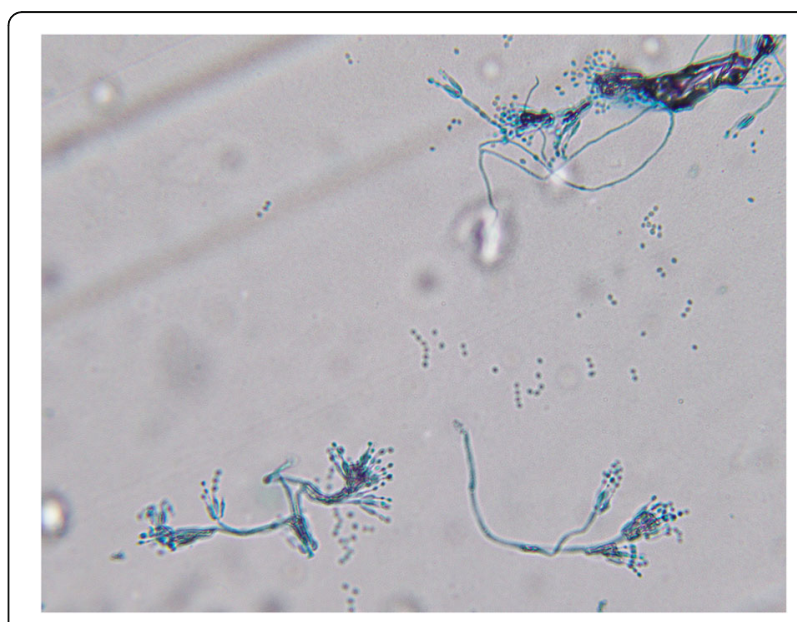

Fig. 5 Septate branching hyphae of P.citrinum showing ampulliform phialides and spherical conidia (lactophenol blue) $(\times 100)$ 
clinicians may consider the possibility of AFOP in cases of pneumonia deteriorated rapidly to respiratory failure and refractory to antimicrobial therapy. AFOP is characterized histopathologically by intra-alveolar deposition of fibrin, features of organizing pneumonia with patchy distribution, and absence of the hyaline membrances [3]. The presence of organized fibrin is the predominant histological finding $[3,7]$.

AFOP is a rare variant of pneumonia with an uncertain etiology. Proposed etiologies include connective tissue disorders, drugs, occupational exposure, immune system disorders, and infections [2, 3, 8-10]. The concomitant occurrence of fungal infection has not been described in patients with AFOP. Our patient appeared to have a fungal infection, which may be $P$. citrinum. $P$. citrinum is ubiquitous in the environment and usually considered as a laboratory contaminant or a nonpathogenic species, as it rarely causes human infection [11-14]. In this case, the patient was initially misdiagnosed as IPA. It is likely that $P$. citrinum shows similar hyaline septate hyphae to Aspergillus on direct microscopic examination. Anyway, fluconazole is not an appropriate treatment for Aspergillus at the local hospital.

We considered $P$. citrinum infection in our patient for the following reasons: (i) The growth of $P$. citrinum in five separate sputum cultures from a symptomatic patient with uncontrolled DM prompted careful consideration of a $P$. citrinum pneumonia; (ii) Pathological biopsy revealed small abscesses and granulomatous nodules, and special stain (PAM) result was positive, suggesting fungal pneumonia; (iii) There was no evidence to confirm infection of other organisms. GM test in BAL fluid was negative which is in contrast with previous reports $[15,16]$. It's likely that our patient was nonagranulocytosis and received voriconazole, to which false-negative GM test results have been attributed. Due to the unpleasant experience, the patient refused to undergo tracheoscopy once more. The case presented herein highlight the potential pathogenic role of $P$. citrinum in immunocompromised hosts. Notably, clinicians should be aware of these usual "contaminative" fungi of low pathogenicity and maintain a high index of suspicion in diagnosing this potentially fatal but treatable disease.

Currently, corticosteroid therapy is the most common and effective treatment for AFOP $[3,17,18]$, as in this case. There is no consensus on the dosage or duration of corticosteroids. Various regimens have been used depending on the severity and progression of the disease. The long-term effects of corticosteroids have not been established; therefore, monitoring the disease progression is recommended, and reassessments may be necessary. Although there are no standard treatment guidelines for patients with penicilliosis, the first-choice treatment regimen is $0.6 \mathrm{mg} / \mathrm{kg} /$ day amphotericin B for 2 weeks, followed by oral itraconazole for 10 weeks [1921]. Voriconazole should not be considered first-line for the empiric treatment of $P$. citrinum [16]. The high MIC of $P$. citrinum isolate in our patient, which is consistent with previous reports $[15,16,22]$, may partly explain why the initial administration of voriconazole was ineffective. Therefore, early antifungal susceptibility testing is essential for appropriate treatment to improve clinical outcomes. Significant relief of symptoms and improvement in radiological findings after the administration of corticosteroids and amphotericin B indicated that the patient received appropriate therapy. However, the patient was treated with corticosteroids and antifungal agents together, it is difficult to understand the effectiveness of antifungal administration.

In summary, we reported an unusual case of AFOP and fungal pneumonia. If clinical symptoms and chest imaging features are unresponsive to broad-spectrum antibiotics, a lung biopsy could be considered and timely performed. As this common "contaminant" can behave as a pathogen in an immunocompromised state, both clinicians and microbiologists should consider the presence of a serious and potentially fatal fungal infection on isolation of $P$. citrinum. Based on this case, it could be speculated that AFOP may occur in association with fungal infection including $P$. citrinum. Our speculation improves the understanding of AFOP. Whether or not $P$. citrinum infection is a risk factor of AFOP needs to be clarified with more investigations and further experiments.

\section{Abbreviations}

AFOP: Acute fibrinous and organizing pneumonitis; DM: Diabetes mellitus; CT: Computed tomography; IIP: Idiopathic interstitial pneumonia; ATS/ ERS: American Thoracic Society/European Respiratory Society; WBC: White blood cell; CRP: C-reactive protein; CAP: Community-acquired pneumonia; GM: Galactomannan; IPA: Invasive pulmonary aspergillosis;

BAL: Bronchoalveolar lavage; $\mathrm{PaO}_{2}$ : Partial pressure of oxygen; $\mathrm{FiO}_{2}$ : Fraction of inspired oxygen; PAM: Periodic acid-silver methenamine; MIC: Minimum inhibitory concentration

\section{Acknowledgements}

Not applicable.

\section{Authors' contributions}

JZ takes responsibility for drafting the manuscript. JZ, DY and XS are the attending doctors of this patient. QS is responsible for Pathological results and WW is for Microbiological results. YS and XS is responsible for revision of the manuscript. All authors read and approved the final manuscript.

\section{Authors' information}

Jiangnan Zhao and Dongmei Yuan are resident physicians-in-training, and Yi Shi, Qunli Shi, Weiping Wang and Xin Su are attending specialist physicians who dedicate their time to mentoring trainees.

Funding

This study was supported by the National Natural Science Foundation of China (Grant 81873400 to Dr. Su) and Jiangsu Province "333 Project" Research Funding (BRA2019339 to Dr. Su). This funding body had no 
influence on the design of the study and collection, analysis, and interpretation of data and in writing the manuscript.

\section{Availability of data and materials}

Data sharing is not applicable to this article as no datasets were generated or analysed.

\section{Ethics approval and consent to participate}

Written informed consent was obtained from the patient to participate in this case report.

\section{Consent for publication}

Written informed consent for publication of clinical details and clinical images was obtained from the patient. A copy of the consent form is available for review by the Editor of the journal.

\section{Competing interests}

The authors have no competing interests to declare.

\section{Author details}

'Department of Respiratory and Critical Care Medicine, Jinling Hospital, Medical School of Nanjing University, Nanjing 210002, China. ${ }^{2}$ Department of Pathology, Jinling Hospital, Medical School of Nanjing University, Nanjing 210002, China. ${ }^{3}$ Department of Clinical Laboratory, Jinling Hospital, Medical School of Nanjing University, Nanjing 210002, China.

Received: 19 November 2019 Accepted: 13 April 2020

Published online: 20 April 2020

\section{References}

1. Travis WD, Costabel U, Hansell DM, King TE, Lynch DA, Nicholson AG, Ryerson CJ, Ryu JH, Selman M, Wells AU, et al. An official American Thoracic Society/European Respiratory Society statement: update of the international multidisciplinary classification of the idiopathic interstitial pneumonias. Am J Respir Crit Care Med. 2013;188(6):733-48.

2. Heo JY, Song JY, Noh JY, Yong HS, Cheong HJ, Kim WJ. Acute fibrinous and organizing pneumonia in a patient with HIV infection and Pneumocystis jiroveci pneumonia. Respirology. 2010;15(8):1259-61.

3. Beasley MB, Franks TJ, Galvin JR, Gochuico B, Travis WD. Acute fibrinous and organizing pneumonia - a histologic pattern of lung injury and possible variant of diffuse alveolar damage. Arch Pathol Lab Med. 2002;126(9):106470 .

4. Hariri LP, Unizony S, Stone J, Mino-Kenudson M, Sharma A, Matsubara O, Mark EJ. Acute fibrinous and organizing pneumonia in systemic lupus erythematosus: a case report and review of the literature. Pathol Int. 2010; 60(11):755-9.

5. Santos C, Oliveira RC, Serra P, Baptista JP, Sousa E, Casanova P, Pimentel J, Carvalho L. Pathophysiology of acute fibrinous and organizing pneumoniaclinical and morphological spectra. Pathophysiology. 2019;26(3-4):213-7.

6. Kligerman SJ, Franks TJ, Galvin JR. From the radiologic pathology archives: organization and fibrosis as a response to lung injury in diffuse alveolar damage, organizing pneumonia, and acute fibrinous and organizing pneumonia. Radiographics. 2013;33(7):1951-75.

7. Schlesinger C, Koss MN. The organizing pneumonias: an update and review. Curr Opin Pulm Med. 2005:11(5):422-30.

8. Chiu KY, Li JG, Gu YY. A case report of acute fibrinous and organizing pneumonia with pneumothorax and avian exposure history. Clin Respir J. 2018;12(2):811-5

9. Valim V, Rocha RH, Couto RB, Paixao TS, Serrano EV. Acute fibrinous and organizing pneumonia and undifferentiated connective tissue disease: a case report. Case Rep Rheumatol. 2012;2012:549298.

10. Otto CHD, Kemna L, Hüttel A, Benk C, Rieg S, Ploenes T, Werner M, Kayser G. Acute fibrinous and organizing pneumonia associated with influenza a/ H1N1 pneumonia after lung transplantation. BMC Pulm Med. 2013:13:30.

11. Gilliam JS, Vest SA. Penicillium infection of the urinary tract. J Urology. 1951; 65(3):484-9.

12. Garg A, Stuart A, Fajgenbaum M, Laidlaw DA, Stanford M. Chronic postoperative fungal endophthalmitis caused by Penicillium citrinum after cataract surgery. J Cataract Refr Surg. 2016;42(9):1380-2.

13. Gugnani HC, Gupta S, Talwar RS. Role of opportunistic Fungi in ocular infections in Nigeria. Mycopathologia. 1978;65(1-3):155-66.
14. Apk TM, YU MY, Ellis DH, Johnson PJ, Wickham NWR. Fatal Penicillium citrinum pneumonia with pericarditis in a patient with acute leukemia. $J$ Clin Microbiol. 1997;35(10):2654-6.

15. Krishnan SG, Sim Tee NW, Tan AL, Tan AM, Aan Koh MJ, Chong CY, Thoon KC, Hui Tan NW. A case of cutaneous penicilliosis in a child with acute myeloid leukaemia. JMM Case Rep. 2015;2(5).

16. Shayla E. Hesse PML, John H. Beigel, Adrian M. Zelazny: Penicillium citrinum: opportunistic pathogen or idle bystander? A case analysis with demonstration of galactomannan cross-reactivity. Med Mycol Case Rep 2017, 17:8-10.

17. Kobayashi H, Sugimoto C, Kanoh S, Motoyoshi K, Aida S. Acute fibrinous and organizing pneumonia - initial presentation as a solitary nodule. J Thorac Imag. 2005;20(4):291-3.

18. Kuza C, Matheos T, Kathman D, Heard SO. Life after acute fibrinous and organizing pneumonia: a case report of a patient 30 months after diagnosis and review of the literature. J Crit Care. 2016;31(1):255-61.

19. Le T, Kinh NV, Cuc NTK, Tung NLN, Lam NT, Thuy PTT, Cuong DD, Phuc PTH, Vinh VH, Hanh DTH, et al. A trial of Itraconazole or amphotericin B for HIVassociated Talaromycosis. N Engl J Med. 2017;376(24):2329-40.

20. Edwards S, Dockrell DH, Nelson M. Special Issue: British HIV Association and British Infection Association Guidelines for the Treatment of Opportunistic Infection in HIV-seropositive Individuals 2011 Introduction. Hiv Med. 2011;12 6-7.

21. Kaplan JE, Benson C, Holmes KK, Brooks JT, Pau A, Masur H, Centers for Disease C, Prevention, National Institutes of H, America HIVMAotIDSo. Guidelines for prevention and treatment of opportunistic infections in HIVinfected adults and adolescents: recommendations from CDC, the National Institutes of Health, and the HIV Medicine Association of the Infectious Diseases Society of America. MMWR Recomm Rep. 2009;58(RR-4):1-207 quiz CE201-204.

22. Guevara-Suarez M, Sutton DA, Cano-Lira JF, Garcia D, Martin-Vicente A, Wiederhold N, Guarro J, Gene J. Identification and antifungal susceptibility of Penicillium-like Fungi from clinical samples in the United States. J Clin Microbiol. 2016;54(8):2155-61.

\section{Publisher's Note}

Springer Nature remains neutral with regard to jurisdictional claims in published maps and institutional affiliations.

Ready to submit your research? Choose BMC and benefit from:

- fast, convenient online submission

- thorough peer review by experienced researchers in your field

- rapid publication on acceptance

- support for research data, including large and complex data types

- gold Open Access which fosters wider collaboration and increased citations

- maximum visibility for your research: over $100 \mathrm{M}$ website views per year

At $\mathrm{BMC}$, research is always in progress.

Learn more biomedcentral.com/submission 